\title{
A beginner's guide to ethnographic observation in nursing research
}

Conroy T (2017) A beginner's guide to ethnographic observation in nursing research. Nurse Researcher. 24, 4, 10-14.

Date of submission: II March 20l6; date of acceptance: 30 August 20l6. doi: I0.7748/nr.20I7.el472

\section{Tiffany Conroy}

Program coordinator and lecturer, School of Nursing, University of Adelaide, Australia

\section{Correspondence} tiffany.conroy@adelaide. edu.au

\section{Conflict of interest}

The author declared no potential conflicts of interest with respect to the research, authorship and publication of this paper.

\section{Peer review}

This article has been subject to external double-blind peer review and checked for plagiarism using automated software

\section{Acknowledgements The author acknowledges the ongoing support for this research project and the encouraging feedback received on drafts of this manuscript from Alison Kitson, Alison Tierney, Kate Cameron, Philippa Rasmussen and Rebecca Feo. The author's $\mathrm{PhD}$ is funded by the Research Training Scheme provided by the Australian Government Department of Education and Training}

\begin{abstract}
Background Observation is mentioned in most ethnographic textbooks, but specific details about how it should be conducted and the practicalities to be considered in ethnographic nursing research are not always explicit. This paper explores the experiences of and challenges faced by a novice nurse researcher who used observation to collect data.
\end{abstract}

Aim To provide a novice researcher's perspective of observation in ethnographic nursing research and to highlight the associated challenges.

Discussion Challenges that arose in observation began with determining which perspective to take, followed by rehearsing observation, developing and maintaining a constructive relationship with the observation site, being aware of the influence of the observer, managing interactions between the observed and the observer, and responding to ethical issues.

Conclusion Novice nurse researchers considering using observation to collect data should be aware of the potential challenges they might encounter.

Implications for practice The information presented in this paper will enable novice researchers to anticipate these issues and develop strategies to prevent or address them.

\section{Keywords}

ethnography, nursing, observation, research, novice researcher, nursing research

\section{Introduction}

This paper is a reflective commentary on conducting observation from the perspective of a novice ethnographic nurse researcher. Although participant observation is mentioned in most ethnographic textbooks, specific details regarding its use in nursing research and the practicalities to be considered are not always explained. Kawulich (2005) provided a comprehensive overview of participant observation; however, this is more than ten years old and is not specific to nursing research. There are many seminal texts that describe the theoretical basis and methodology for ethnography (Spradley 1980, de Laine 1997, Schensul et al 1999, Hammersly and Atkinson 2007, Murchinson 2010), however, there are few publications that address the practical experiences of engaging in ethnographic research (Gelling 2014).

This paper provides a perspective on conducting observation as part of nursing research. It is intended not to be a critical examination of observation as a methodology, but to provide practical tips that might help novice ethnographic researchers, especially nurses. It describes the background to a study, for which I undertook observation, and explores the issues encountered, including determining the perspective of the observer; rehearsing observation and deciding what to document; achieving a constructive relationship with the observation site; the influence of the observer; interactions between the observed and the observer; ethical issues; and staying 'neutral'. I then use my experience of these issues to suggest matters to consider when observing and to present some strategies that could be helpful.

\section{Background to the study}

A major challenge in nursing is ensuring the 'basics' or fundamentals of care are carried out correctly. These have traditionally been the responsibility of nurses and include ensuring patients receive appropriate nutrition, hydration, hygiene, sleep and dignity (Kitson et al 2013a).

The aim of my doctoral research is to investigate the challenges in providing these 
fundamentals. It involves three phases, and the methods used to collect data include observation, focus groups and interviews. The first phase - completed in 2014 - involved observing interactions between nurses and between nurses and patients that were related to the fundamentals of care. I observed participants two hours per day for five days in four different clinical areas of an acute care hospital in South Australia. This phase is the focus for this paper. Phase two involved the development of scenarios based on the findings from these data, which were presented to focus groups of nurses and patient representatives for comment. Phase three will involve interviews with nurses exploring issues raised in the focus groups.

\section{Using ethnography and observation in nursing research}

The use of ethnography in nursing research is not a recent phenomenon (Gelling 2014). Ethnography has been used since the early 1900s when the use of observation to collect data was established (de Laine 1997). These observations, recorded as field notes, remain a primary source of data for ethnographic research (Robinson 2013).

Observation has been defined as 'the systematic description of event, behaviours, and artefacts in the social setting chosen for study' (Marshall and Rossman 1989), and can describe the communication patterns, workflows and tasks of the clinicians in a specific work environment (Horsky and Mamykina 2012). Observation is considered integral to ethnography as it provides the best opportunity to view participants' behaviour in the context of the 'real world' (Fetterman 2010).

\section{The perspective of the observer}

The influence of observing from the perspective of either a participant ('emic') or a nonparticipant/observer ('etic') needs to be considered (de Laine 1997). This is explored in the literature along with descriptions of the various possible roles of the observer (Gold 1958, Spradley 1980, Baker 2006), which can range from being a participant who conceals their being a researcher from others ('complete participant') to being an observer of whom participants are unaware ('complete observer') (Table 1). Ethnographers differ on the merits of these various roles (Spradley 1980, Fetterman 2010), while Baker (2006) suggested various roles can be used during observations.

The observation in my research might be considered 'complete observation', for example, as I was not directly involved in

care. However, because I am a registered nurse and did occasionally assist participants in minor ways, such as helping to make beds and fetch equipment, it could also be argued I was a participant. Potentially, I was a 'passive participant', according to Spradley (1980)'s types of participant/observer, which Spradley suggested is a valuable way to understand the cultural rules people follow. I was also an 'observer as a participant': participants were aware I was observing them and I participated in activities, which might have helped to develop a positive relationship with the observation site and those being observed.

\section{Rehearsing observation}

Taking field notes is 'part of the invisible oral tradition' of ethnography (Hammersly and Atkinson 2007). As a novice observer, it is difficult to know if you are seeing what you are looking for and recording what is needed. The thought of spending many hours collecting data only to discover that they do not answer your research question is anxietyprovoking.

Sampson (2004) supported the piloting of data collection before ethnographic fieldwork as a way to improve the quality of a study. Before the first period of observation, it was valuable to me to practise observation and trial the collection of data. I developed a draft tool that included prompts for information about the events I would observe, including location, date, time and the participants involved. I also included an area for free text.

I piloted the tool in one of the proposed observation sites, in tandem with an

\section{TABLE I. Observer roles}

Role type

The complete participant

The participant as an observer

Moderate role or peripheral member

The observer as a participant

The complete observer (passive participation)

Non-participation

\section{Online archive} For related information, visit nurseresearcher. com and search using the keywords
Be fully part of the setting. Observation is often hidden from those being observed.

Has access to the research setting by having a natural, non-research reason for being present. Part of the group being studied. Actively participates in group activities.

Balance between participation and observation. Interacts with those being observed and engages in similar activities. Not considered a member of the group.

Only minimal involvement in the research setting. More observation than participation.

Does not take part in the setting at all. Role is to listen and observe.

Not present at the setting. 
experienced nurse researcher. We documented our findings and recorded our reflections on the trial, including feeling welcomed at the site, which might have been because some of the staff knew us personally. The people we were observing were registered nurses (RNs) and, as we were RNs too, we were conscious of needing to take off our ' $\mathrm{RN}$ hats' when describing what we were actually seeing, not what we inferred or assumed.

For example, if a nurse approached a patient with a small syringe, lifted the bed covers to expose the patient's thigh and injected a clear substance into the patient's leg, an observing nurse might assume this was the administration of subcutaneous heparin. The observing nurse would need to acknowledge this emic view and instead consciously adopt an etic view as an outside observer.

It also became apparent that verbatim descriptions of every detail of the observed events would generate considerable data, so observation would need to be targeted and focused on the research questions. To minimise the amount of writing required, I developed a list of codes and abbreviations for commonly observed phenomena. I revised the data collection tool to incorporate these changes.

Having an experienced nurse researcher as a co-observer during the pilot also provided moral support and a way to determine if the data collected were 'fit for purpose'. A comparison of our observations confirmed the focus and depth of data needed. It also gave me some reassurance I was recording the 'right' thing.

Some researchers suggest taking detailed notes throughout a period of observation (Kneafsey et al 2013, Kjerholt et al 2014) whereas others prefer to focus on actively observing, recording the detail later (Fetterman 2010). I chose to transcribe the data from the tool immediately after each observation period, and add my recollections and reflections to each event. Data were transcribed with details of the date, time, place and participants, and a description of the event. This enabled easier recollection of what had occurred. However, the time I took to transcribe data was almost as long as the time taken to collect them, so I chose to limit all observation sessions to two hours.

\section{Achieving a constructive relationship with the observation site}

I conducted observations at sites nominated by their staff following a request sent by the director of nursing of the hospital on my behalf. Before commencing observations, I met with each of the leaders of the ward areas and as many staff as possible, to describe the study and obtain their support. I attended ward handover meetings to explain the study and distribute information about participation.

I was known at the pilot observation site, which I also used as the inaugural site for the research. This existing relationship enabled the collection of the initial data to occur in an environment where I was welcome. It was helpful to be in a familiar environment with friendly faces, and I could practice explaining the purpose of the research and asking staff and patients for consent for observation. Moving to unfamiliar sites was then less daunting because I had my 'pitch' and processes practised and smooth.

Across all four observation sites, most nurses who were approached or were 'volunteered' by the senior staff were gracious and welcoming. Only one nurse refused to be observed, saying she was 'too busy'.

Kawulich (2005) suggested that having existing personal contacts, being recognisable to the participants and 'hanging out' at the site can develop trust and rapport. Novice observers who do not already have relationships with their observation sites should spend some time making themselves known, explaining their projects and, if possible and appropriate, helping with participants' workloads in some way (Simmons 2007). Not only will this provide an alternative perspective of the behaviour that is to be observed, it could enable the participants to become more familiar and comfortable with the researchers' presence.

\section{The influence of the observer}

Being watched can change a person's behaviour. There is a risk that those being observed censor themselves or stage performances (Monahan and Fisher 2010). Although I was attempting to obtain as much data as possible, I tried to be unobtrusive or avoid becoming involved in potentially sensitive or irrelevant activities. I observed at a distance and I did not accompany the nurses I was observing behind closed doors or curtains. This was congruent with my research question. However, if this type of information had been required, I would have needed to have negotiated access.

I used a clipboard to record events, which led to some healthcare staff assuming I was conducting an audit of hand-hygiene several made a demonstrable effort to be seen washing their hands. Any decrease in hospital-acquired infections could not be attributed to my presence! 
Those being observed would sometimes want to explain their actions and would apologise for closing doors to maintain the patients' privacy during some procedures. I reassured them these apologies were unnecessary.

Observation sites varied in whom they allocated me to observe. Some seemed keen to show off their more experienced staff to 'show me how it's done'; others seemed to want to protect their staff, so allocated inexperienced or relief staff. If sites and their staff feel their provision of care might be judged and reported to their managers, they might be less willing to be involved (de Melo et al 2014). This was not the aim of my research and I stressed this in the information supplied, but other researchers might need to reinforce this message at every observation.

\section{Staying "neutral"}

Ethnographers must make their biases explicit the 'ethnographer enters the field with an open mind not an empty head' (Fetterman 2010). They can also use strategies such as triangulation and a non-judgmental orientation to reduce the influence of their biases (Fetterman 2010).

Pellat (2003) highlighted the need to be conscious of any potential biases, which for me included being a $\mathrm{RN}$, my previous employment at the observation site, and my prior co-authorship of papers concerning the Fundamentals of Care (Kitson et al 2010, Kitson et al 2013a, Kitson et al 2013b, Kitson et al 2014). My strategies to address these possible biases included making reflective notes after each observation period, regular debriefing and discussion with my PhD supervisors, and reorganising the data. I collected and chronologically transcribed the data, then collated them into patient-specific events for analysis. This informed the next phases of the research, which provide an opportunity for triangulation and additional opportunities to address these biases.

I recorded verbatim what I saw and heard. Some events had positive and negative emotional effects. When transcribing the data, I reflected on these events and recorded my responses to them. These events tended to be at the forefront of my recollection of the data, which could have influenced which examples I extracted to demonstrate certain themes. To avoid this, a moderation process was required that involved other researchers familiar with the data but not present during observation.

\section{Ethical issues}

When preparing for my study, I identified several potential ethical requirements.
These included obtaining informed consent from those being observed, maintaining confidentiality and anonymising participants' data.

To obtain informed consent, before beginning the observations I explained the proposed research in detail and distributed information sheets to all potential participants at each site. Patients and nurses could all refuse to be observed or choose to withdraw from the study at any time. I recorded no personal identifying information, so any potential risk of harm for participants was unlikely.

The research ethics committee at the hospital approved blanket consent for the observation, with an opt-out for any person who did not wish to be observed. When seeking ethical approval, I also needed to explain how I would react if I witnessed any risk to a participant's safety. This subsequently happened on two occasions when a patient was in distress and no one else was present: the first involved a patient attempting to climb over bed rails, the second when a patient urgently required a bedpan and was becoming distressed. Although I was recording how and when nurses responded to patients' needs, allowing actual harm and distress to occur would not be ethical behaviour for a $\mathrm{RN}$, so I intervened. Having already considered how I would respond before being confronted with these situations enabled me to avoid any personal ethical conflict.

\section{Other reflections}

The focus of the study was an area where there was little previous research, so I tried to maximise the variety of observations. I observed different participants and sites at different times of day, to try to obtain a broad overview of practice (Lambert et al 2011). However, other researchers might want an indepth understanding of only a single topic and so choose to concentrate their observations appropriately.

Observation generates considerable data: in my study, 40 hours of observation turned into more than 28,000 transcribed words. Word counts increased for each site as data collection progressed - this might reflect my familiarity with the processes and my ability to better describe the details surrounding the events or perhaps there were simply more events in the areas that I observed later in the study.

Table 2 contains a summary of these issues and some possible strategies to prevent or address them; these strategies reflect the learning of a novice ethnographer.
Write for us journals.rcni.com/r/ nr-author-guidelines 


\begin{tabular}{|c|c|}
\hline Elements of observation & Considerations \\
\hline Preparing to observe & Decide how you will initially position yourself as an observer. \\
\hline Rehearsing observation & $\begin{array}{l}\text { "Practise observing and be prepared to modify what you are doing based on this experience. } \\
\text { "Use of a co-observer in the early stages could be helpful to ensure data collected are focused } \\
\text { on the research question. }\end{array}$ \\
\hline $\begin{array}{l}\text { What to record and how } \\
\text { to record it }\end{array}$ & $\begin{array}{l}\text { " Focus or vary your observations as required to address your research question. } \\
\text { "Use of a data collection tool and codes for frequently occurring items could assist. } \\
\text { " Allow time immediately or soon after the observation period to transcribe your field notes } \\
\text { while memories are fresh. } \\
\text { " Be prepared for a lot of data. }\end{array}$ \\
\hline $\begin{array}{l}\text { Achieving a constructive } \\
\text { relationship }\end{array}$ & $\begin{array}{l}\text { "If possible, start in a familiar site. } \\
\text { - It might not affect your data collection but you will feel more comfortable. } \\
\text { - You can develop your strategies for observation distance and duration, (non)intervention, } \\
\text { and responding to interactions. } \\
\text { " Be prepared for varying degrees of welcome. } \\
\text { » If you are not in a familiar place, spend some time making yourself and your project known. } \\
\text { "Where possible and appropriate, contribute in a helpful way. }\end{array}$ \\
\hline Influence of the observer & Know that being watched might change how people behave. \\
\hline Managing interactions & $\begin{array}{l}\text { Ensure those being observed are clear about the aims of the research and they do not think they } \\
\text { need to compromise patient privacy to accommodate your observations. }\end{array}$ \\
\hline Ethical issues & Ensure informed consent and confidentiality. \\
\hline Staying 'neutral' & $\begin{array}{l}\text { "Reflect on your observations and record your responses. } \\
\text { " A moderation process involving other researchers is useful. }\end{array}$ \\
\hline
\end{tabular}

\section{Conclusion}

Observation is a fundamental part of ethnography. This paper contains reflections from a novice ethnographer on personal experiences of observation. It provides an overview of some of the issues that can arise during observation, highlights some of the matters to be considered, and provides strategies that other nurse researchers can use during observation.

\section{References}

Baker LM (2006) Observation: a complex research method. Library Trends. 55, 1, 171-189.

de Laine M (1997) Ethnography: Theory and Applications in Health Research. MacLennan \& Petty Pty, Sydney NSW.

de Melo LP, Stofel NS, Gualda, DM et al (2014) Nurses' experiences of ethnographic fieldwork. Nurse Researcher. 22, 1,14-19.

Fetterman DM (2010) Ethnography Step-By-Step. Third edition. Sage Publications, Thousand Oaks CA.

Gold R (1958) Roles in sociological field observation. Social Forces. 36, 217-213

Gelling L (2014) Complexities of ethnography. Nurse Researcher. 22, 1, 6-7.

Hammersley M, Atkinson P (2007) Ethnography: Principles in Practice. Third edition. Routledge, Abingdon.

Horsky J, Mamykina L (2012) Ethnographic Observation Methods. www.nist.gov/it//iad/upload/
Horsky-Ethnographic-Methods.pdf (Last accessed: February 20 2017.)

Kawulich BB (2005) Participant Observation as a Data Collection Method www qualitative-research. net/index.php/fas/article/view/466/996 (Last accessed: February 202017 .)

Kitson A, Conroy T, Wengstrom Y et al (2010) Defining the fundamentals of care. International Journal of Nursing Practice. 16, 423-434.

Kitson A, Conroy T, Kuluski Ket al (2013a) Reclaiming and Redefining the Fundamentals of Care: Nursing's Response to Meeting Patients' Basic Human Needs. School of Nursing, the University of Adelaide, Adelaide SA

Kitson A, Roberston-Malt S, Conroy T (2013b) Identifying the Fundamentals of Care within Cochran Systematic reviews: the role of the Cochrane Nursing Care Field Fundamentals of Care Node. International Journal of Nursing Practice. 19, 109-115.

Kitson A, Muntlin Athlin A, Conroy T (2014) Anything But Basic: Nursing Challenge in Meeting Patients'
Fundamental Care Needs, Journal of Nursing Scholarship. 46, 5, 331-336

Kjerholt M, Wagner L, Delmar C et al (2014) Continuity in care trajectories of older chronically ill patients in a battlefield of competing rationales. International Journal of Older People Nursing. 9, 4, 277-280.

Kneafsey R, Clifford C, Greenfield S (2013) What is the nursing team involvement in maintaining and prompting the mobility of older adults in hospital? A grounded theory study. International Journal of Nursing Studies. 50, 12, 1617-1629.

Lambert V, Glacken M, McCarron M (2011) Employing an ethnographic approach: key characteristics. Nurse Researcher. 19,1,17-24.

Marshall C, Rossman GB (1989) Designing Qualitative Research. First edition. Sage Publications, Newbury Park CA.

Monahan T, Fisher JA (2010) Benefits of "observe effects": lessons from the field Qualitative Research, $10,3,357-376$.
Murchinson JM (2010) Ethnography Essentials: Designing, Conducting and Presenting Your Research. Jossey-Bass, San Francisco CA.

Pellatt G (2003) Ethnography and reflexivity: emotions and feelings in fieldwork. Nurse Researcher. 10,3, 28-37.

Robinson SG (2013) The relevancy of ethnography to nursing research. Nursing Science Quarterly. $26,1,14-19$

Sampson H (2004) Navigating the waves: the usefulness of a pilot in qualitative research. Qualitative Research 4,3,383-402.

Schensul SL, Schensul JJ, LeCompte MD (1999) Essential Ethnographic Methods: Observations, Interviews, and Questionnaires. Altamira Press, Plymouth.

Simmons M (2007) Insider ethnography: tinker, tailor researcher or spy? Nurse Researcher. 14, 4,7-17.

Spradley JP (1980) Participant Observation. Wadsworth, Belmont CA. 